\title{
Willingness to pay for travel insurance as a risk reduction behavior: health-related risk perception after the outbreak of COVID-19
}

\author{
Yeongbae Choe ${ }^{1} \cdot$ Hyesun $\mathrm{Kim}^{2} \cdot$ Youngjoon $\mathrm{Choi}^{3}$
}

Received: 30 October 2020 / Accepted: 12 January 2022 / Published online: 27 January 2022

(c) The Author(s), under exclusive licence to Springer-Verlag GmbH Germany, part of Springer Nature 2022

\begin{abstract}
This study aims to identify the effects of health-related risk perception and sociodemographic characteristics on the willingness to pay (WTP) for travel insurance as a risk reduction behavior following the outbreak of COVID-19. Through the application of a double-bounded dichotomous choice contingent valuation method, this study found several determinants for travel insurance price (i.e., risk perception toward traveling, perception about the influence of COVID-19, past travel insurance purchase experience, age, and education). The mean WTP was estimated to be approximately KRW 11,700 (USD 10.23). Several theoretical and managerial implications regarding risk perception and travel insurance are discussed.
\end{abstract}

Keywords Risk perception · Travel insurance $\cdot$ COVID-19 $\cdot$ Risk reduction behavior - Willingness to pay

Hyesun Kim

hyesun@wsu.ac.kr

Yeongbae Choe

ychoe@gachon.ac.kr

Youngjoon Choi

young.choi@ewha.ac.kr

1 Department of Tourism Management, College of Social Sciences, Gachon University, 1342

Seongnamdaero, Sujeong-gu, Seongnam-si, Gyeonggi-do 13120, Republic of Korea

2 Department of Hotel and Tourism Management, Woosong University, 171 Dongdaejeon-ro, Dong-gu, Daejeon 34606, Republic of Korea

3 Department of International Office Administration, College of Science and Industry Convergence, Ewha Womans University, 52 Ewhayeodae-gil, Seodaemun-gu, Seoul, Republic of Korea 


\section{Introduction}

The COVID-19 pandemic (declared by the World Health Organization on March 12,2020 ) has severely impacted the global tourism and hospitality industry unlike any other previous historical crisis [other infectious disease outbreaks (e.g., severe acute respiratory syndrome or SARS, Middle East respiratory syndrome or MERS, and the swine flu pandemic caused by the H1N1 virus)]. According to United Nations World Tourism Organization (UNWTO 2020), the global international tourist arrivals in the first half of 2020 decreased by $20-30 \%$ over the same period last year, resulting in a loss of 440 million tourists globally and about USD 460 billion damages economically. This impact is much greater than that of the SARS pandemic in $2003(0.4 \%$ decrease $)$ or any other disease outbreaks previously reported.

As of September 2021, COVID-19 has been gaining traction across countries for more than a year now. In the meantime, several vaccines have been launched worldwide, and considerable attention has been focused on tracking variants [e.g., Alpha (earliest documented in the UK, Sep. 2020), Beta (earliest documented in South Africa, May 2020), Gamma (earliest documented in Brazil, Nov. 2020), and Delta (earliest documented in India, Oct 2020)] (Darby and Hiscox 2021). These variants have different characteristics (e.g., contagiousness, mortality rate) but the Delta variant has been the most dominant in most countries until Omicron is taking over recently. Despite the launch of several vaccines, the number of confirmed cases has still increased sharply in recent days due to the Delta variant, which is highly contagious in comparison to previous variants (Jung 2021). This is true even for some countries with a high vaccination rate. Therefore, this phenomenon, observed globally, has severely slowed down the speed of recovery within the tourism and hospitality industry. At the same time, countries have implemented several measures, such as compulsory temperature measurement, quarantine upon entry, or mandatory certificates, travel bubbles, and health passports, to attempt to control cross-border travel and avoid disease outbreaks (Phelan 2020).

Given the magnitude of COVID-19, several scholars (e.g., Gössling et al. 2020; Kock et al. 2020; Sigala 2020) have emphasized the significant and unprecedented impacts of the pandemic, including the transformation of the tourism and hospitality industry in general and drastic changes in tourist behaviors after the outbreak of COVID-19 (i.e., during and post-COVID-19 era). Existing studies call for further research in examining this recent phenomenon and the potential changes that have occurred in the tourism and hospitality industry. From the perspective of tourists, the COVID-19 pandemic has greatly reduced their needs/ wants to travel, along with the overall tourism demand, either forcefully or voluntarily. Additionally, many countries and regions have imposed travel restrictions and lockdowns to avoid potential threats from human mobility (e.g., Gössling et al. 2020; Wen et al. 2020). Meanwhile, many people are suffering from anxiety and fear because of their perceived physical and economic vulnerability amid COVID-19 (Kock et al. 2020). Destinations, marketers, and practitioners 
now need to understand tourist risk perception and risk reduction behaviors concerning the COVID-19 pandemic among the many possible changes to revive tourist confidence and encourage them to participate in traveling during and post-pandemic.

Tourist risk perception has a vital role in their travel decision-making process and subsequent behaviors (Karl 2018; Kock et al. 2020). Several studies on tourism and travel health have found that tourists' risk perceptions negatively influence the tourism demand and the intention to visit tourist destinations (Sonmez and Graefe 1998a, b; Williams and Baláž 2013; Pizam et al. 2004). Interestingly, Fuchs and Reichel (2006) found that perceived risks (i.e., vulnerability and severity) have an even stronger effect on tourists' decision making and destination choices than actual risks. Meanwhile, tourism scholars have devoted substantial effort toward identifying and characterizing various risk types associated with travel, such as natural disaster risk, physical risk, psychological risk, social risk, health, political instability, and terrorism (Roehl and Fesenmaier 1992; Sonmez and Graefe 1998a, b; An et al. 2010). Among various risk perceptions, risks related to safety and security are the strongest factors influencing destination choice as they are directly associated with individuals' physical well-being (Karl 2018). Similarly, the relationship between perceived risk and proximity tourism is mediated by the attitude toward COVID-19 (Lebrun et al. 2021). This implies that perceived risk would change one's attitude toward the risk, which in turn, impacts their intention to proximity tourism.

Considering the current severe impact of COVID-19, this study focuses mainly on such health risks associated with personal safety issues. Health-related risks are closely related to tourists' safety and security during their travel and could influence the same health issues and problems of host communities (Wilks 2006). People react differently (i.e., avoidance, modification, or protective behaviors) based on demographic characteristics and the level of risk perception they hold (Sonmez and Graefe 1998a; Fuchs and Reichel 2011; Uriely et al. 2007). Indeed, a recent study (Chua et al. 2021) empirically demonstrated that health risk perception could change one's mental well-being and perception of uncertainty, ultimately influencing short- and long-term travel avoidance (such as seen during the recent COVID19 pandemic). To cope with one's health-related risk issues, tourists purchase travel insurance, which is the most popular and simplest strategy for tourists who want to continue their travel-related activities without modification (Mitchell and Vassos 1998; Sarman et al. 2019; Lo et al. 2011). Travel insurance covers potential negative incidents during travel and financially supports tourists when they need to resolve issues (e.g., medical treatment, lost luggage, canceled flights) (Kerr and Kelly 2018). Therefore, travel insurance could be a feasible but an easy risk reduction option in order for tourists to avoid any unpleasant consequences due to potential risks while traveling to a destination.

Therefore, this study is designed to understand tourists' risk perception toward COVID-19 and its effect on purchasing travel insurance. Specifically, this study attempted to assess the monetary value of tourists' risk perception toward traveling after the outbreak of COVID-19. Further, it attempted to identify the determinants of travel insurance purchases by employing a double-bounded dichotomous choice contingent valuation method (DB-DCCVM) as an analytic framework. The findings 
have theoretical and managerial implications for travel insurance, risk perception, and tourists' decision making.

The paper is structured as follows: in the literature review section, tourist risk perception, travel insurance as a risk reduction strategy, and determinants affecting the purchase of travel insurance are discussed to present the research framework. The following section outlines the study methods, including data collection and analysis. In the result section, the findings from the proposed method are described, both at the aggregated level and separate levels (previously purchased travel insurance and no experience). Finally, concluding remarks, theoretical and practical implications, limitations, and suggestions for future research are offered in the last section.

\section{Literature review}

\subsection{Risk perception}

The concept of risk perception has been studied in various contexts. In the tourism and hospitality industry, tourists' risk perceptions are considered one of the most important factors determining various travel-related behaviors guiding the decisionmaking processes (Reichel et al. 2007; Sonmez and Graefe 1998a, b). While various scholars have attempted to define risk perception, the most widely accepted definition is, "the amount and types of risk potential tourists associated with international tourism" (Sonmez and Graefe 1998a). Many empirical studies have repeatedly confirmed the negative influence of risk perception on tourists' decision making and behaviors. Travelers often hesitate to visit a certain destination due to safety issues from risk situations (e.g., war, crime, terrorist attack, disasters). Moreover, risk perception toward tourist destinations negatively impacts destination preference, image, and brand, eventually leading to a decrease in tourists' intention to visit a destination (Sonmez and Graefe 1998b; Baloglu and McCleary 1999; An et al. 2010). Tourists might change their travel-related behaviors (e.g., shorten the length) or delay their travel plans after resolving their concerns about risky situations (Chew and Jahari 2014; Sonmez and Graefe 1998a). As tourism involves many stakeholders and situations, different risk types have drawn attention. Roehl and Fesenmaier (1992) identified seven types of risk (i.e., equipment, financial, physical, psychological, satisfaction, social, and time) based on consumer behavior models. Sonmez and Graefe (1998a, 1998b) additionally considered health, political instability, and terrorism risks.

In the context of COVID-19, this study focuses on health risks and their effects on an individual's decision-making process. By nature, travelers favor the exploration of new or unfamiliar situations and being away from their ordinary life; therefore, they are often exposed to many challenges, such as cultural, psychological, physiological, emotional, environmental, and health challenges (Jonas et al. 2010; Sarman et al. 2019; Wilks et al. 2006). These challenges may cause physical illness (e.g., injury, death) or mental or emotional illness (e.g., stress, disorder) because of issues and events during their travel. The characteristics and environmental conditions of destinations (e.g., altitude, climate, hygiene, and diseases) could also 
endanger tourists' safety and health during and after travel (Cossar 2003). More recently, Jonas et al. (2010) identified various health risk perceptions (e.g., water quality, health care quality, food safety, infectious diseases, physical injury, sexually transmitted diseases, and drug use). Interestingly, earlier efforts in the tourism industry (Sonmez and Graefe 1998b, a; Reichel et al. 2007) discovered that the effects of health risks on destination choice are rather weaker than those of other types of risk. Recent studies have focused on the diverse aspects of health-related perceptions and their behavioral outcomes (e.g., protective behavior, destination choice). Mizrachi and Fuchs (2016) identified the following three key discussion themes in an online travel forum concerning the Ebola virus in Africa: positive thinking and encouragement, knowledge development and preparation, and personal risk assessment. According to Lee et al. (2012), the perception toward H1N1 does not directly influence desire and behavioral intention, but it exerts an indirect effect on behavioral intention through non-pharmaceutical interventions for H1N1. These results align with earlier studies (e.g., Sonmez and Graefe 1998b, a; Reichel et al. 2007), thus indicating that tourists might be still willing to travel to a certain destination despite the potential health risks if they believe that they can prevent diseases or illnesses by adopting protective behaviors.

A recent study by Chen et al. (2020) categorized tourism-related diseases into six-different categories based on the main reasons/routes of disease transmission. Evidently, the tourism and hospitality industry is highly susceptible to health risks, particularly highly infectious diseases such as MERS, H1N1, SARS, or COVID-19. Such diseases have certainly contributed to significant downturns in international travel demand (Shi and Li 2017). Thus, the UNWTO and numerous governments have devoted much effort toward warning potential tourists of the possible dangers from traveling or related activities, and increasing public awareness of possible risk reduction and protective behaviors. Tourism scholars have also focused on explaining why and how individuals participate in risk reduction behaviors while confronting health-related risks. Risk reduction behaviors have been further investigated from the aspects of avoidance or substitution of a destination, tourists' behaviors while traveling to potentially dangerous destinations, or the approach to providing proper information (Sonmez and Graefe 1998a; Uriely et al. 2007; Fuchs and Reichel 2011). These studies emphasized that tourists do not always cancel or postpone their travel plans despite being aware of risk situations at their destinations; driven by their risk perception, they instead increase their information searching behavior and preparation for risk reduction behaviors. In accordance with recent research, this study focuses on the relationships between risk perception and risk reduction behavior (i.e., purchase of travel insurance) in assessing the influence of risk perception on the willingness to pay (WTP) for travel insurance.

\subsection{Travel insurance as a risk reduction strategy}

Movement while traveling potentially puts individuals in danger depending on the situation at their particular destination. To avoid potential risks, reduce uncertainties, and minimize negative consequences, people often adopt various forms of risk 
reduction behaviors (e.g., seeking advice from others, relying on a travel agency, obtaining additional information, purchasing travel insurance, and availing of vaccinations) (Mitchell and Vassos 1998; Fuchs and Reichel 2011; Sarman et al. 2019; Lo et al. 2011). With the development of information technology and social media, travelers can now use their phones to refer to online reviews and join online forums to seek advice from other tourists and check the necessary travel information (Fuchs and Reichel 2011). Among various travel-related risk-reduction strategies, travel insurance and vaccinations are widely considered to avoid potentially negative consequences (Mitchell and Vassos 1998; Jonas et al. 2010). However, while availing of vaccinations appears to be the least common behavior adopted by tourists, purchasing travel insurance has emerged as the most popular and easiest strategy for tourists (Mitchell and Vassos 1998; Lo et al. 2011; Sarman et al. 2019; Kerr and Kelly 2018). This trend is attributable to the increased number of international travels and independent travelers (Leggat and Leggat 2002). This study only considers travel insurance as a risk reduction strategy during and after the COVID-19 pandemic. Focusing solely on travel insurance is sensible because a vaccine against COVID-19 has yet to become available at the time of the study design and data collection for the current study.

Travel insurance is a special type of insurance product (or service) that exclusively applies to tourists and travel activities. Travel insurance typically covers travel-related risks to which travelers are likely exposed and provides financial compensation in case these unforeseen risks put travelers in harm's way (Hasan and Abdullah 2015). Typical travel insurance products supplement existing medical or health insurance products that usually do not cover events during travel (Leggat et al. 1999). In practice, travelers can become insured in several ways (i.e., purchasing travel insurance and availing of insurance offered by credit card companies and travel companies). Travel insurance coverage may vary; thus, it may cover loss of baggage, trip cancellation, physical injury, medical treatment, or any unforeseeable situations during one's travel. By purchasing travel insurance, travelers can bear such risks financially while traveling, but the decision might be based on a comparison between the expected cost of such risks and the cost of travel insurance (Hasan and Abdullah 2015). Therefore, travel insurance may provide travelers with financial security against potential health risks, strengthen their confidence in traveling by providing a sense of safety, and reduce their sensitivity to perceived risks (Tykocinski 2008; Sarman et al. 2019).

\subsection{Determinants affecting travel insurance purchase}

Tourists have varying levels of tolerance against perceived/actual risks, and perceptions exceeding such levels prompt them to consider certain decisions that mitigate these risks and uncertainties (i.e., risk reduction/protective behavior and abandonment of travel plans) (e.g., Fuchs and Reichel 2011; Lo et al. 2011; Sonmez and Graefe 1998a). The varying levels of risk tolerance lead to different levels of travel insurance purchase intention. A relatively limited number of studies in the tourism and hospitality field have explored travel insurance and risk 
perception (Kerr and Kelly 2018; Sarman et al. 2019). These studies have identified several variables as important predictors and determinants affecting travel insurance purchase.

First, tourists' risk perception is a primary motivation toward purchasing travel insurance. Kock et al. (2020) found a positive relationship between perceived COVID-19 infectability and the intention to book travel insurance. This finding is supported by prior studies on risk reduction, risk perception, and travel insurance. Purchasing travel insurance is a risk reduction strategy that requires a certain level of risk perception and intention to travel. If people perceive a high level of risk toward a destination, then they are most likely to choose one of the best options (e.g., canceling their plans, modifying their plans, including changing their destination, or engaging in other protective behaviors, such as performing an information search and purchasing travel insurance) (Mitchell and Vassos 1998; Lo et al. 2011; Karl 2018). Chien et al. (2016) showed that travel risk perception, determined by worry and sensation-seeking propensity, increases travelers' risk protective behaviors. More recently, Sarman et al. (2016) found that risk perception and risk categories greatly affect the likelihood of young tourists to accept life-threatening hazards. Chou and Yao (2011) also reported that travelers visiting China tend to purchase travel insurance if they have a high level of risk perception and are willing to pay a premium. Thus, a high-risk perception level due to COVID-19 will likely lead to an increased intention to purchase travel insurance.

Second, individual characteristics (e.g., gender, age, income, and education) could also serve as important determinants of travel insurance purchase decisions. Many earlier studies in tourism and public health repeatedly tested the effects of demographic factors on risk perception, risk reduction strategies, and the likelihood of purchasing travel insurance, but their results are generally mixed. For example, Lo et al. (2011) showed differences in demographics (i.e., age, gender, and income) between various segment groups based on risk reduction strategies. Sonmez and Graefe (1998b) found that education level greatly affects the decision to travel internationally, but they did not report the same effect for age and gender. A recent study (Sarman et al. 2019) also showed mixed results (i.e., income and age show a significant effect on the likelihood to purchase travel insurance, but the same is not true for gender). Karl (2018) also reported remarkable differences in age and education between tourists' typology based on risk and uncertainty, but they did not observe any effect of gender and income. Zalech (2020) found that age and the level of monthly income are significant factors in determining travel insurance purchase; gender and education were not identified as such factors. Chou and Yao (2011) showed differences in the effects of monthly income, education, and age on the likelihood of purchasing travel insurance, but they did not observe any effect of gender. Meanwhile, Chou and Yao (2011), Lo et al. (2011), and Zalech (2020) found an inverted U-shaped relationship between age and the intention to purchase travel insurance (i.e., middle-aged groups are more likely than young and old travelers to purchase travel insurance). Considering these mixed results, this study intends to investigate the effects of demographic factors (i.e., age, gender, monthly income, and education) on travelers' intention to purchase travel insurance following the outbreak of COVID-19. 
Third, past purchase experience potentially creates different behaviors when people face risky situations. The purchase of travel insurance provides travelers with psychological benefits (e.g., safety, security, competence, or even comfort) and financial benefits (e.g., medical and related travel expenses) (Hasan and Abdullah 2015; Leggat et al. 1999; Tykocinski 2008; Sarman et al. 2019; Kerr and Kelly 2018). Considering travel insurance as a risk reduction strategy, people may repeatedly purchase travel insurance if they believe that doing so can mitigate potential risks. Yu and Chen (2018) found empirical evidence that the frequency of past insurance purchase increases people's intention to purchase travel insurance online. Travel insurance varies widely depending on travel type, which may come in the form of domestic travel, international travel, or both. The type of travel insurance could be a proxy for the tendency of a traveler to purchase travel insurance in this context. Therefore, this study argues that past insurance purchase experience for the three travel types would change the propensity toward purchasing travel insurance.

\section{Methodology}

\subsection{Study design}

This study used a DB-DCCVM to assess how much tourists would be willing to pay for travel insurance to reduce the risks associated with traveling in a described hypothetical scenario. This method is also utilized to understand which factors drive tourists' WTP for travel insurance after the outbreak of the COVID-19 pandemic. In various studies based on the contingent valuation method (CVM), respondents are often asked to report their willingness to participate in or perform a certain behavior under a hypothetical market scenario. In such situations, respondents often provide their responses in a way that maintains their utilities at a certain level even after changes in market situations and product conditions occur (Hanemann 1994; Mitchell et al. 1989). Theoretically, the CVM is rooted in the random utility maximization of microeconomic theory, which assumes that people always attempt to maximize their benefits (i.e., utility and welfare) by paying a certain amount of money for products, services, or goods (McFadden 1974). Individuals' WTP is derived using the concept of welfare changes (e.g., economic value and benefit) contingent on changes in the given hypothetical situation (e.g., attribute, availability) rather than the changes in price.

A dichotomous choice CVM involves less cognitive burden for respondents and provides potentially less biased results than an open-ended CVM (Arrow et al. 1993; Hanemann 1994; Mitchell et al. 1989) A DB-DCCVM includes two sequential sets of choice under the same hypothetical situation but at different prices. Compared with a single-bounded CVM (an SB-DCCVM), which consists of a single CVM question, this method provides a specific WTP range by having an additional set of questions in a DB-DC format. Therefore, a DB-DCCVM could have its advantages over an SB-DCCVM-(1) it can accurately estimate individuals' WTP with great certainty based on an efficient analytical approach and (2) by having a second set of questions, a DB-DCCVM could reduce its number of sample requirements 
(Hanemann et al. 1991). The second set of questions is based on the first set of responses and a given price, and subsequently asks the same questions under the same hypothetical scenario either at a higher price (twice or one and a half times that of the original price depending on the study design) when the first answer is a "yes" or at a lower price (one-half or two-thirds times) when the first answer is a "no." As such, a DB-DCCVM was used in the present study to ascertain tourists' WTP for travel insurance as a risk reduction strategy, whereby tourists benefit from purchasing travel insurance to reduce their potential risk compared to the scenario of traveling without any insurance.

Following the recommendations of Arrow et al. (1993) and Mitchell et al. (1989), the survey procedure and hypothetical market scenario were carefully designed to reflect a real decision-making situation by providing a detailed description of current and hypothetical situations, including a realistic payment method and a suitable question format. The survey questionnaire consists of three parts. The first part includes questions measuring the respondents' perception of the influence of COVID-19 and their risk perception toward traveling. In this process, the study utilized a single-item measurement for each component (i.e., influence on daily life, influence on travel activities, and risk perception toward traveling). A single-item measurement is acceptable in measuring raters' perception toward a specific concept if the object and attributes are concretely explained in the question (Dolnicar 2013). Moreover, one question about the respondents' experience in purchasing travel insurance was included to control the potential effects of previous experience on individuals' WTP. The second part of the survey explains the current situation and hypothetical changes. The description of the current situation covers the current state of COVID-19 in South Korea and the potential reason as to why travel insurance could be considered when planning future trips. Such a form of description ensures a certain level of background knowledge before asking a CVM question. Although Korean governments provide financial support to patients for medical treatment, the current travel insurance for domestic travel in South Korea does not cover potential risks due to infections while traveling (e.g., COVID-19, SARS); such coverage differs from that for international travel. COVID-19 patients may also require additional financial support for living expenses or potential post-COVID symptoms after their initial recovery. At the time of the data collection, Korean governments encouraged travelers to enjoy domestic travels as an effective way to overcome various psychological symptoms caused by COVID-19 and to boost the country's economy. Thus, the actual CVM question is whether respondents would be willing to pay for travel insurance while planning for domestic travel. The monetary values were generated based on the actual prices of travel insurance (which does not cover disease infection at the time of data collection), and their feasibility was confirmed in a pilot test. Each respondent was asked the first question with a randomly assigned price (i.e., KRW 1000; KRW 2500; and KRW 4000) for the initial bid price and the subsequent question with a higher or lower price according to their initial response (twice or one-half the initial price). The last part of the survey asks for demographic information (e.g., gender, age, monthly income, and education).

Before the survey was administered, the questionnaire was sent to three tourism professors who previously conducted studies related to tourism economics, 
economic valuation, and risk perception. The questionnaire was then reviewed regarding the appropriateness of each question, especially for payment vehicle and payment price. After revising the questionnaire based on their comments, ten graduate students at the university in Korea participated in a pre-test to reaffirm the prepared questionnaire for data collection. Several words and sentences were modified to improve the readability and clarity of the survey questions. The survey questionnaire was explicitly developed mainly for the Korean population; however, it did not include any pre-validated measures from previous studies and did not conduct a back-transition technique. Instead, the questionnaire and the manuscript were sent to two tourism professors, fluent in both Korean and English, who confirmed whether the translated work or results differed from their original meaning in the survey questionnaire to ensure the quality of the content in this study.

\subsection{Data collection}

This study collected data via an online survey of Korean adults in late August 2020 through the largest survey company in South Korea (Embrain, www.embrain.com). In late August 2020, the number of COVID-19 patients in South Korea was relatively stable. Hence, the Korean government actively promoted domestic travel to support the local economy and cope with COVID-19-related depression among citizens. To ensure the sample's representativeness, we used a quota sampling procedure while selecting the sample. The quota was calculated based on the distribution of gender and age across the entire Korean population. Initially, 3802 survey invitations were sent out, and of this number, 827 individuals responded. However, only 512 responses were recorded as valid because of the quota status or due to incomplete responses. Some questionable responses were then disregarded (e.g., insincere responses, reasonably short or long response times), resulting in 470 completed responses for use in the empirical analysis. The final response/completion rate was $13.47 \%$, and the effective response rate was $12.36 \%$. As no statistical difference was noted between our sample and the Korean population (gender: $\chi^{2}=0.98, p>0.05$; age: $\left.\chi^{2}=0.75, p>0.05\right)$, the sample was deemed representative of the Korean population.

\subsection{Model specification}

In the DB-CVM, two sequential bid amounts ( bid $_{1}$ : 1 st bid amount, bid $_{2}: 2$ nd bid amount) were presented to the respondents. Thus, four possible WTP ranges were derived based on the respondents' answers (Fig. 1).

The CVM is theoretically based on the random utility framework for assessing the WTP of respondents from two sequential responses. Thus, the utility in this framework consists of two components, namely, a systematic component and a random component.

$$
U=V(D, M, S)+\varepsilon,
$$




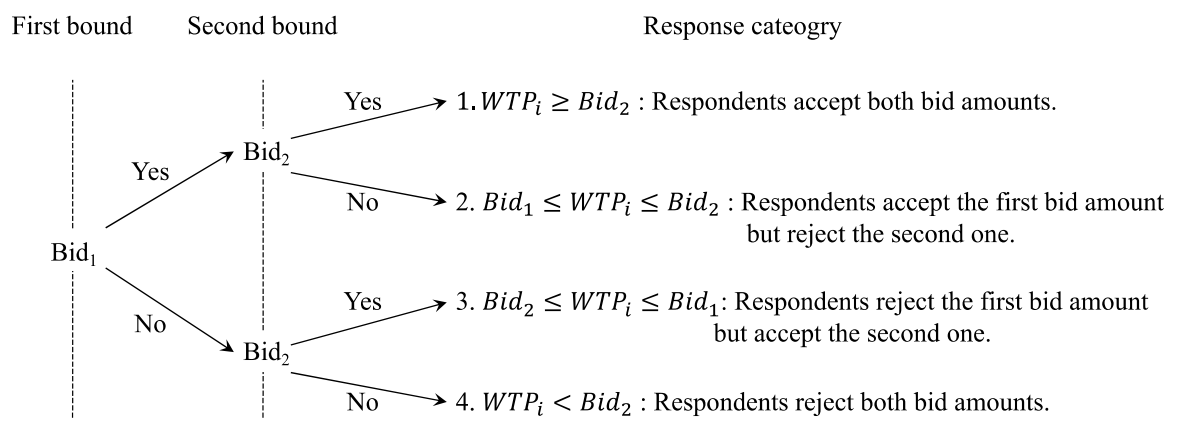

Fig. 1 Possible choices of DB-CVM

where $V=$ deterministic component, $\varepsilon=$ random component, $M=$ income, $S=$ individual characteristics, and $D=$ condition of a given hypothetical situation ( $1=$ implemented, $0=$ status quo).

According to the aforementioned equation, the respondents would be willing to pay for the bid amount (i.e., bid $_{\mathrm{i}}$ ) in the hypothetical scenario only if they expect a high utility from such a scenario. This condition can be expressed in the following equation:

$$
V\left(1, M-\text { bid }_{\mathrm{i}} ; S\right)+\varepsilon_{1} \geq V(0, M ; S)+\varepsilon_{0}
$$

The above equation indicates that the utility of a hypothetical situation (i.e., change in status, purchasing travel insurance in this study) even after paying for the bid amount, is greater than the utility of the status quo without any change in income.

For the actual estimation procedure, the error component in the WTP function is unobservable; therefore, only WTP probability (answer of "yes" or "no") can be obtained in the model. As Hanemann et al. (1991) suggest, DB-CVM data can be assessed in the following econometric model:

$$
\mathrm{WTP}^{\mathrm{i}}=\tau+\varepsilon^{\mathrm{i}},
$$

where $i=$ each respondent, $\tau=$ mean response, $\varepsilon=$ random components assuming a normal distribution.

With the above equation, the probability of choosing among four possible responses can be expressed as follows:

(1) Yes-yes response: $\operatorname{Prob}\left(\tau+\varepsilon^{\mathrm{i}} \geq \operatorname{Bid}_{2}\right)$

(2) Yes-no response: Prob $\left(\mathrm{Bid}_{2}-\tau>\varepsilon^{\mathrm{i}} \geq \mathrm{Bid}_{1}-\tau\right)$

(3) No-yes response: Prob $\left(\mathrm{Bid}_{1}-\tau>\varepsilon^{\mathrm{i}} \geq \mathrm{Bid}_{2}-\tau\right)$

(4) No-no response: $\operatorname{Prob}\left(\tau+\varepsilon^{\mathrm{i}} \leq \operatorname{Bid}_{2}\right)$

A likelihood function of the $i$ th individual response $\left(L^{\mathrm{i}}\right)$ would be the product of all four probabilities; therefore, the equation can be expressed as follows: 


$$
\begin{aligned}
L_{\mathrm{i}}= & \operatorname{Prob}\left(\tau+\varepsilon^{\mathrm{i}} \geq \operatorname{Bid}_{2}\right) \times \operatorname{Prob}\left(\operatorname{Bid}_{2}-\tau \geq \varepsilon^{\mathrm{i}} \geq \operatorname{Bid}_{1}-\tau\right) \\
& \left.\times \operatorname{Prob}\left(\operatorname{Bid}_{1}-\tau \geq \varepsilon^{\mathrm{i}} \geq \operatorname{Bid}_{2}-\tau\right) \times \operatorname{Prob}\left(\tau+\varepsilon^{\mathrm{i}} \leq \operatorname{Bid}_{2}\right)\right)
\end{aligned}
$$

\section{Findings}

\subsection{Respondents' characteristics}

Table 1 shows the characteristics of the samples used in this study. The gender distribution of the 470 respondents is almost equal (men: $50.43 \%$, women: $49.57 \%$ ). The average age of the respondents is approximately 45 years old; those in their $40 \mathrm{~s}$ $(22.98 \%)$ and $50 \mathrm{~s}(22.13 \%)$ comprise the most dominant age group, followed by those in their $60 \mathrm{~s}$ or above (19.15\%), $30 \mathrm{~s}(18.51 \%)$, and $20 \mathrm{~s}(17.23 \%)$. Almost half of the respondents obtained a 4-year university degree $(57.45 \%)$. For the monthly household income, approximately $50 \%$ of the respondents have a monthly household income of at least KRW 4,000,000 (equivalent to USD 3500), that is, KRW $6,000,000$ or above (25.96\%), KRW 5,000,000-5,999,999 (15.53\%), and KRW $4,000,000-4,999,999$ (14.89\%). Slightly less than half (44.89\%) of the participants had no experience purchasing travel insurance. A majority of those with such experience ( $72.97 \%$ in the experienced group; $40.21 \%$ in total) previously purchased travel insurance for international travel alone, followed by those who purchased travel insurance for both domestic and international travel $(16.21 \%$ in the experienced

\begin{tabular}{|c|c|c|c|c|c|}
\hline & Freq & $\%$ & & Freq & $\%$ \\
\hline Gender & & & Monthly income (Unit : 1000 & & \\
\hline Male & 237 & 50.43 & Below 1000 & 13 & 2.77 \\
\hline Female & 233 & 49.57 & 1000-1999 & 28 & 5.96 \\
\hline Age $(M=44.94, S D=13.37)$ & & & 2000-2999 & 83 & 17.66 \\
\hline $20-29$ & 81 & 17.23 & 3000-3999 & 81 & 17.23 \\
\hline $30-39$ & 87 & 18.51 & $4000-4999$ & 70 & 14.89 \\
\hline $40-49$ & 104 & 22.13 & $5000-5999$ & 73 & 15.53 \\
\hline $50-59$ & 108 & 22.98 & 6000 or above & 122 & 25.96 \\
\hline 60 or above & 90 & 19.15 & Travel insurance experience & & \\
\hline Education & & & No experience & 211 & 44.89 \\
\hline High school or below & 75 & 15.96 & Only domestic travel & 28 & 5.96 \\
\hline 2-year College & 72 & 15.32 & Only International travel & 189 & 40.21 \\
\hline 4 year University & 270 & 57.45 & Both travel & 42 & 8.94 \\
\hline Post graduate & 53 & 11.28 & Marriage & & \\
\hline Having a child in family & & & No & 147 & 31.28 \\
\hline No & 34 & 10.53 & Yes & 311 & 66.17 \\
\hline Yes & 289 & 89.47 & Others & 12 & 2.55 \\
\hline
\end{tabular}

Table 1 Respondents characteristics $(n=470)$

Freq. $=$ Frequency, $\%$ Percentage 
Table 2 COVID-19 influence and risk perception

\begin{tabular}{clllllll}
\hline & \multicolumn{2}{l}{ Distribution } & & & M & SD \\
\cline { 2 - 6 } & Strongly disagree & Disagree & Neutral & Agree & Strongly agree & & \\
\hline Influence on daily life & 3 & 10 & 39 & 261 & 157 & 4.189 & 0.724 \\
& $0.64 \%$ & $2.13 \%$ & $8.30 \%$ & $55.53 \%$ & $33.40 \%$ & & \\
Influence on travel & 4 & 9 & 34 & 162 & 261 & 4.419 & 0.779 \\
activities & $0.85 \%$ & $1.91 \%$ & $7.23 \%$ & $34.47 \%$ & $55.53 \%$ & & \\
Risk perception toward & 1 & 0 & 21 & 159 & 289 & 4.564 & 0.601 \\
traveling & $0.21 \%$ & $0.00 \%$ & $4.47 \%$ & $33.83 \%$ & $61.49 \%$ & & \\
\hline
\end{tabular}

$M$ Mean, $S D$ Standard deviation

group; $8.94 \%$ in total) and domestic travel only (10.81\% in the experienced group; $5.96 \%$ in total). Two-thirds of the respondents (66.17\%) are married. Of this group, about $90 \%$ have at least one child.

Table 2 shows the respondents' perception of the influence of COVID-19 and the risk related to traveling. For all three measures, most respondents believed that COVID-19 impacted their daily lives (agree or strongly agree $=88.94 \%$, mean $=4.189$ ) as well as travel activities (agree or strongly agree $=90.00 \%$, mean $=4.419$ ). Moreover, the risk perception toward traveling was extremely high (agree or strongly agree $=95.32 \%$, mean $=4.564$ ). This finding may allow us to speculate the need for travel insurance and how important it may be due to the increased perceived health risk brought about by the COVID-19 pandemic.

\subsection{Model estimates}

This study establishes a model to assess the monetary value of tourists' risk perception toward traveling after the outbreak of COVID-19 by considering travel insurance as a risk reduction behavior. In our analytical approach, several influencing factors (e.g., bid amount, risk perception, demographic characteristics, and travel insurance purchase experience) are considered to predict the WTP (i.e., WTP for travel insurance). Although the initial model includes all potential influencing factors in the dataset, improvements to the model are made by eliminating a number of factors (i.e., gender, marriage, and children in the family) based on the significance of the variables in the model and the AIC values; thus, the process follows a generalto-specific approach (Song et al. 2008). To compare the models between the inexperienced and experienced groups in the context of purchasing travel insurance, we include all factors that emerged as significant predictors for one of the models (i.e., aggregated model, inexperienced group, and experienced group).

\subsubsection{Aggregate model estimation}

We first draw a figure to check the basic assumption that people are less likely to purchase travel insurance as the price increases. Figure 2 displays the probability 


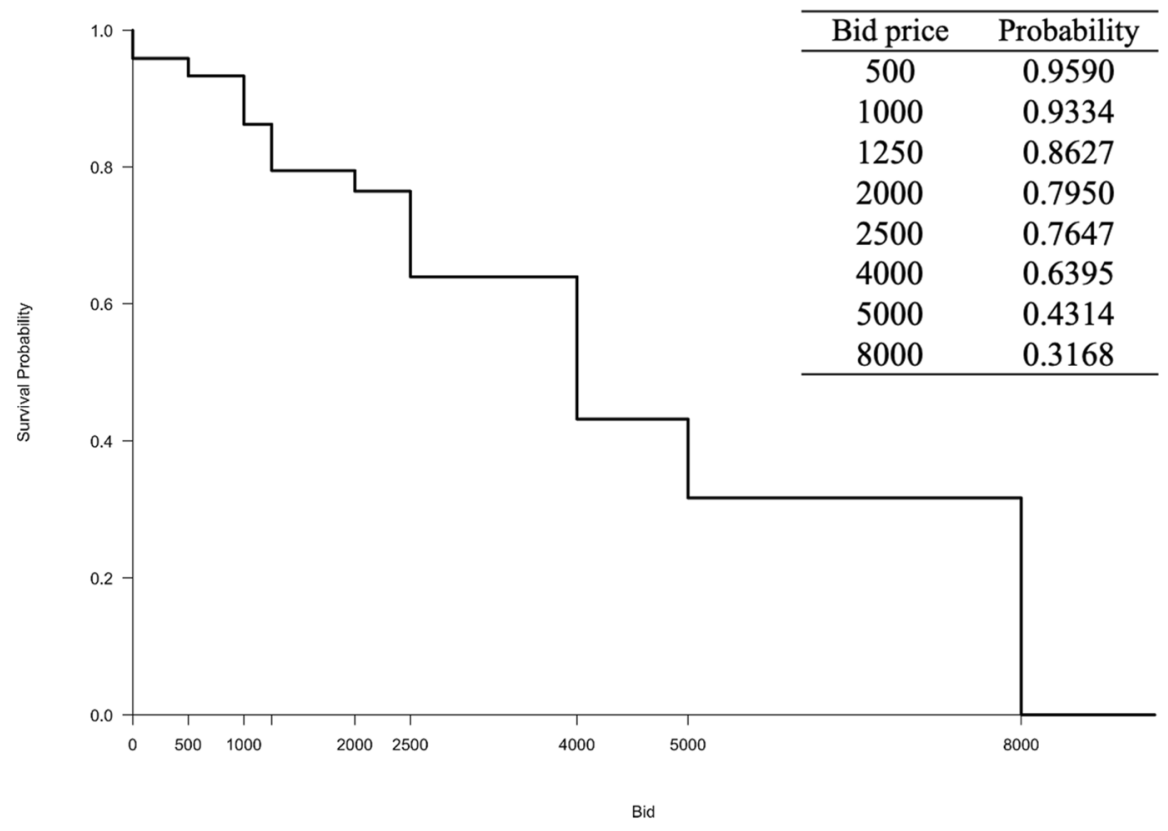

Fig. 2 Probability of purchasing travel insurance under our hypothetical scenario

of purchasing travel insurance under this hypothetical scenario (i.e., traveling during and after the COVID-19 pandemic). As expected, the probability of purchasing travel insurance drops as the price goes up. Hence, the respondents are less likely to say "yes" in a hypothetical situation when the price is high. By applying the Kaplan-Meier-Turnbull nonparametric approach the mean WTP for travel insurance of the respondents was calculated to be 4481.48 .

Following this, a parametric approach is used to analyze a DB-DCCVM utilizing the R package DC choice. As shown in Table 3, the bid amount (log-transformed) in the model is statistically significant at the $1 \%$ level, and the coefficient is negative $(\beta=-0.783, p<0.001)$, as expected. Thus, the higher the travel insurance price, the less likely the respondents' willingness to purchase. Regarding the influence of COVID-19 and the related risk perception, all three perceptions demonstrate a statistically significant positive relationship regarding the choice of purchasing travel insurance in the model. Among the three variables, risk perception toward traveling had the greatest impact on the probability of purchasing travel insurance $(\beta=1.098, p<0.001)$, followed by influence on travel activities $(\beta=0.521, p<0.01)$, and daily life $(\beta=0.340, p<0.05)$. These findings indicate that the probability of purchasing travel insurance will increase as the perception of risk and COVID-19 increases. For the travel insurance purchase experience group (reference group $=$ no purchase experience), the respondents who purchased insurance for both international and domestic travel before are more likely to purchase travel insurance again, as it demonstrates a positive significance (for both travel types: $\beta=1.488, p<0.01$ ). Further, this result suggested 


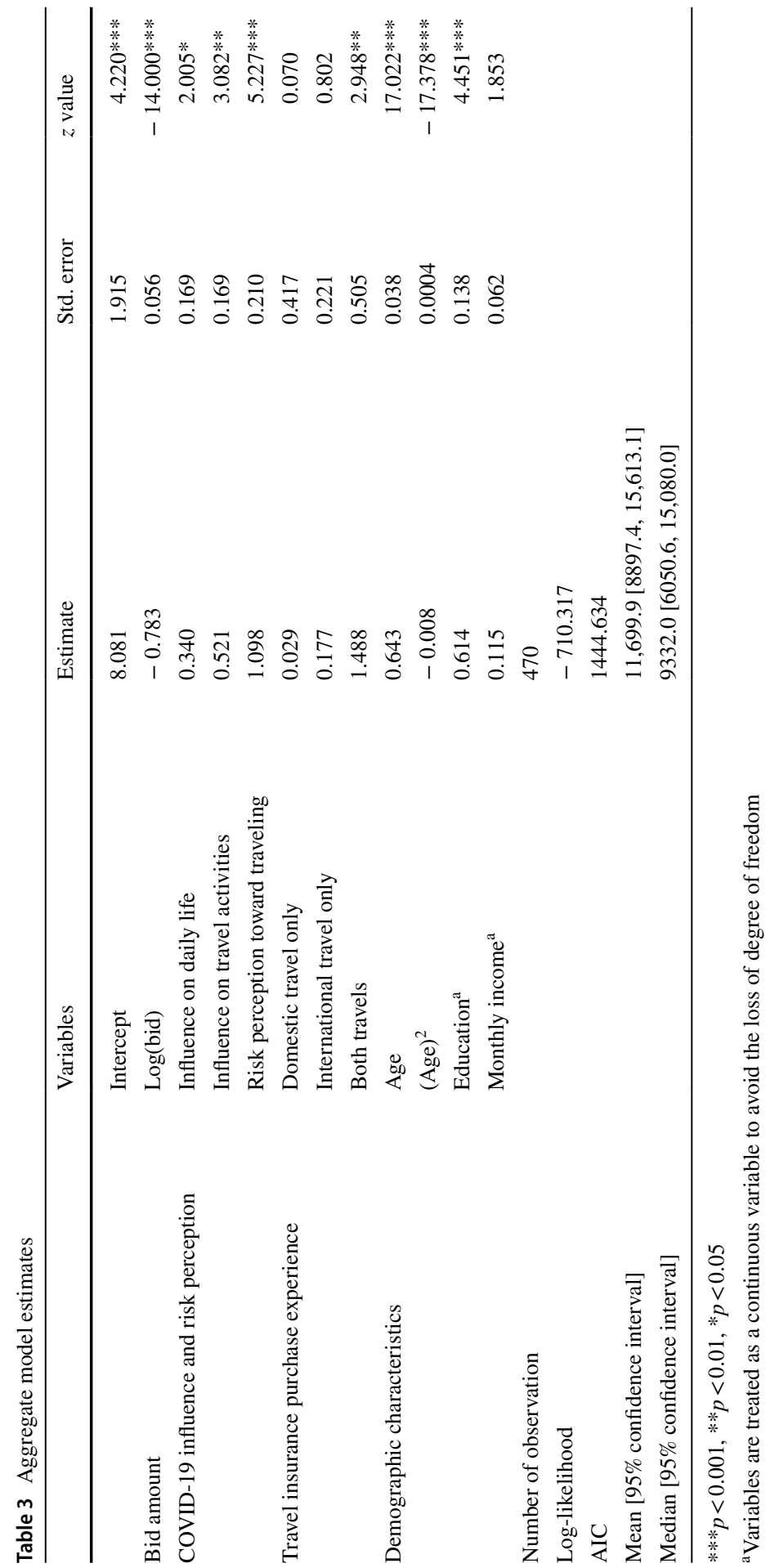


that the probability of purchasing travel insurance does not differ between the other two groups (i.e., domestic travel only or international travel only). Among the demographic variables, age (and its quadratic form), and education, are statistically significant at the $1 \%$ significance level. While the age of respondents demonstrates a "U"-shaped relationship with one's willingness to purchase, education level has a positive significance. More specifically, the findings suggest that the educated respondents are willing to pay more when they purchase travel insurance. Thus, the age variable presents an inverted "U"-shaped relationship regarding the probability of purchasing travel insurance. Surprisingly, monthly income does not exert any significant influence on the aggregated model estimation.

Finally, this study calculates the adjusted truncated mean and median WTP by using the method proposed by Boyle et al. (1988) and Krinsky and Robb (1990). The mean WTP (price per night) is approximately KRW 11,700 (equivalent to 10.23 USD), and a 95\% confidence interval is noted between KRW 8900 and KRW 15,600. Meanwhile, the median WTP (price per night) is KRW 9332 (8.16 USD, 95\% CI: [6050.6, 15,080.0]). This result indicates that our respondents are willing to pay an average of KRW 11,700 to reduce their potential health risk while traveling, and that half of the population is willing to pay at least KRW 9332 for such risk reduction behaviors.

Table 4 Separate model estimates-no experience vs. experienced groups

\begin{tabular}{|c|c|c|c|}
\hline & Variables & $\begin{array}{l}\text { No experience } \\
\text { Estimate (SE) }\end{array}$ & $\begin{array}{l}\text { Experienced } \\
\text { Estimate (SE) }\end{array}$ \\
\hline & Intercept & $-2.309(1.537)$ & $-4.157(2.174)$ \\
\hline Bid amount & $\log ($ bid $)$ & $-1.128(0.116)^{* * *}$ & $-1.520(0.138) * * *$ \\
\hline \multirow{3}{*}{$\begin{array}{l}\text { COVID-19 influ- } \\
\text { ence and risk } \\
\text { perception }\end{array}$} & Influence on daily life & $-0.262(0.214)$ & $0.665(0.254)^{* *}$ \\
\hline & $\begin{array}{l}\text { Influence on travel activi- } \\
\text { ties }\end{array}$ & $0.001(0.190)$ & $0.829(0.257)^{* *}$ \\
\hline & $\begin{array}{l}\text { Risk perception toward } \\
\text { traveling }\end{array}$ & $1.015(0.287) * * *$ & $0.983(0.275)^{* * *}$ \\
\hline \multirow{4}{*}{$\begin{array}{l}\text { Demographic } \\
\text { characteristics }\end{array}$} & Age & $0.398(0.013) * * *$ & $0.087(0.019)^{* * *}$ \\
\hline & $(\text { Age })^{2}$ & $-0.004(0.000) * * *$ & $-0.001(0.000)^{* * * *}$ \\
\hline & Education $^{\mathrm{a}}$ & $0.368(0.168)^{*}$ & $0.429(0.174)^{*}$ \\
\hline & Monthly income ${ }^{a}$ & $0.162(0.085)$ & $0.622(0.100)^{* * *}$ \\
\hline $\begin{array}{l}\text { Number of Obser- } \\
\text { vation }\end{array}$ & & 211 & 259 \\
\hline Log-likelihood & & -281.488 & -318.655 \\
\hline $\mathrm{AIC}$ & & 580.976 & 655.310 \\
\hline $\begin{array}{l}\text { Mean [95\% confi- } \\
\text { dence interval] }\end{array}$ & & $7263.3[5719.1,9347.6]$ & $10,773.3[8519.7,14,274.6]$ \\
\hline $\begin{array}{l}\text { Median [95\% confi- } \\
\text { dence interval] }\end{array}$ & & $4666.2[3439.8,6368.5]$ & $7248.7[5801.9,9523.1]$ \\
\hline
\end{tabular}

$* * * p<0.001, * * p<0.01, * p<0.05$

${ }^{\mathrm{a}}$ Variables are treated as a continuous variable to avoid the loss of degree of freedom 


\subsubsection{Differences between purchase experiences}

To further understand the role of the previous purchase experience, this study separately analyzed the same model (i.e., inexperienced and experienced groups) (Table 4). The direction of each path in the model is the same as those shown in the aggregated model. The bid amount for both models is statistically significant at the $1 \%$ significance level, and the coefficients are both negative. Thus, the typical demand law is also applied to this context, indicating that the probability of purchasing travel insurance decreases as the given bid amount increases. The coefficient for the experienced group $(\beta=-1.520, p<0.001)$ is greater than that for the inexperienced group $(\beta=-1.128$, $p<0.001)$; the experienced group has a more elastic demand for purchasing travel insurance as a risk reduction behavior. Regarding risk perception and the influence of COVID-19, only risk perception is shown to be statistically significant for the inexperienced group; the other three perceptions (such as risk perception toward traveling, travel activities, and daily life) are statistically significant for the experienced group. In both models, the significant coefficients have positive signs, implying that risk perception can increase one's willingness to purchase. Interestingly, risk perception toward traveling was significant in both models, but the impact of risk perception is slightly greater for the inexperienced group $(\beta=1.015, p<0.001)$ than for the experienced group ( $\beta=0.983, p<0.001)$. Nonetheless, the influence of COVID-19 on daily life and travel activities is only significant for the experienced group. This result could be attributed to the fact that the experienced group is relatively sensitive to the possibility of risk situations emerging during travel, the severity of COVID-19, and the vulnerability of their daily life and travel activities due to the COVID-19 pandemic. Regarding the demographic factors, both groups show an inverted "U"-shape curve for age. Additionally, there is a significant positive effect of education. Noticeably, monthly income is the only significant factor for the experienced group; yet, this is not true for the inexperienced group.

The estimation procedure utilized for the mean and median WTP and the 95\% confidence interval is implemented for the aggregated model and applied to the inexperienced and experienced groups. No statistically significant difference is noted in the mean and median WTP between the two groups. The mean and median WTP for the inexperienced group are approximately KRW 7300 (6.38 USD, 95\% confidence inter$\mathrm{val}=[5719.1,9347.6])$ and KRW 4670 (4.08 USD, 95\% confidence interval $=[3439.8$, 6368.5]), respectively. Meanwhile, the mean and median WTP for the experienced group are KRW 10,800 (9.44 USD, 95\% confidence interval $=[8519.7,14,274.6])$ and KRW 7250 (6.34 USD, 95\% confidence interval $=[5801.9,9523.1]$ ), respectively. In the current study, despite the non-statistical difference, we cannot neglect the finding that the experienced group is more willing to pay for travel insurance than the inexperienced group. 


\section{Conclusion and implications}

\subsection{Conclusion}

The COVID-19 pandemic has greatly increased the potential tourists' risk perception toward all types of travel-related activities, which in turn, significantly weakens tourists' desire to travel. Therefore, this study considered the purchase of travel insurance as an effective risk reduction strategy for potential tourists during and after the COVID-19 pandemic. By using a DB DCCVM, this study confirmed that the influence of COVID-19 and risk perception, demographic factors (age and education level), and past travel insurance purchase experience would influence tourists' WTP for travel insurance when faced with health-related risk issues. This study also found differences in the determinants of purchasing travel insurance between the two groups (who varied in travel insurance purchase experience). The findings are expected to contribute to the literature on travel insurance and risk perception both theoretically and practically.

\subsection{Theoretical implications}

First, this study considered travel insurance as an effective risk reduction behavior following the outbreak of COVID-19 and our findings are consistent with those of earlier studies (e.g., Sarman et al. 2019; Zalech 2020; Lo et al. 2011; Sonmez and Graefe 1998b). In our study, the perception of COVID-19 and the subsequent risk perception toward traveling emerged as important determinants of purchasing travel insurance, thereby confirming the role of travel insurance as a risk reduction behavior in tourists' decision-making process. The more risk-sensitive tourists are, the more willing they are to purchase travel insurance to ensure their compensation in cases of negative incidents while traveling. In the post-COVID era, the role of travel insurance may be more important and subject to more effective communication between insurance companies and travelers (Tan and Caponecchia 2021). However, to do so, insurance companies (or insurers) must carefully consider various characteristics of tourists such as risk perception and attitude toward risk. More importantly, this study gathered evidence on the differences between general risk traits and domain-specific risk traits. Individuals may show varied responses toward risk perceptions in general situations and specific travel behaviors (Williams and Baláž 2013; Pizam et al. 2004). In this study, risk perception toward traveling was a statistically significant influencing factor for all respondents; however, the perception of the influence of COVID-19 (e.g., the influence on daily life and travel activities) was not associated with the likelihood of purchasing travel insurance for those who had never purchased travel insurance before. Thus, this study included two separate variables explaining the influence of COVID-19 on daily life and travel activities. As such, tourists may not simply engage in certain protective behaviors because of their perception of the influence in general; they tend to re-evaluate the possibility of being influenced by such risks while engaging in a specific activity or making a particular trip-related decision. 
Second, this study expands upon existing literature on the relationship between socio-demographics and risk reduction behaviors (i.e., travel insurance purchases). Earlier studies have shown mixed effects of demographics on risk perception and insurance purchase. In this study, the respondents' age presented an inverted "U"shaped effect on travel insurance purchase, and this result is consistent with those of Chou and Yao (2011), (Lo et al. 2011), and Zalech (2020). Moreover, the result showed that middle-aged respondents were more intent on purchasing travel insurance than their younger and older counterparts. Education level was also found to be related to purchasing travel insurance, thus confirming the findings of Sonmez and Graefe (1998b), Karl (2018), and Chou and Yao (2011). Meanwhile, monthly income and gender did not show a significant effect. This finding can be explained by the concept of risk competence and tolerance (Williams and Baláž 2013; Tykocinski 2008). As such, people may negotiate between different values, needs, situations, and practices that align with their perception of risk in particular situations (Williams and Baláž 2015; Karl 2018). Different sociodemographic factors may lead to different levels of competence, negotiation processes, and levels of risk tolerance, all of which may in turn cause people to engage in different risk reduction behaviors. As such, the finding of this study echoes the importance of further investigations into health-related risk perceptions and other relevant concepts (e.g., risk sensitivity, negotiation between risky situations and risk reduction behaviors).

Third, the findings may expand the discussion on heterogeneity in risk sensitivity observed in past travel insurance purchase experiences. In consumer behavior literature, past experience is a strong factor that guides future behaviors. Similarly, the frequency and past experience of purchasing travel insurance increase the tendency to purchase travel insurance for future travels (Sarman et al. 2019; Tykocinski 2008; Kerr and Kelly 2018). In this study, past travel insurance purchase experience significantly increased the WTP for travel insurance. Interestingly, different effects of risk perception on travel insurance purchase were determined between the two groups with varying experiences of purchasing travel insurance. Among the many possible explanations, this study refers to the concept of "experience use history." This concept represents the accumulated experience and knowledge that one has in the past within a type of participation (Schreyer et al. 1984). In our study, this concept could explain the tendency to purchase travel insurance while planning future travel largely because of an individual's accumulated experience. Thus, with different levels of experience use history, the respondents in our sample demonstrated different levels of sensitivity toward insurance price and risk perception. In line with the discussion on the difference between domain-specific and general risk traits, our findings suggest that risk sensitivity for traveling may not always be the same as that for other behaviors or risk sensitivity in general.

\subsection{Managerial implications}

This study provides meaningful implications for practitioners. First, our findings show the importance of target marketing practices in travel insurance. In our study, several demographic factors (e.g., age, monthly income, and education) and past 
purchase experience were related to the respondents' levels of WTP for travel insurance. Insurance companies and travel agencies could utilize such information to prepare different marketing and promotional materials aimed toward different target groups. Advanced technologies could also help companies in distributing appropriate advertisements and promotional materials. Second, insurance companies could design different coverages for their insurance products. In our aggregated model, the perception of COVID-19 and the risk perception while traveling were significant determinants of the travel insurance price. This result implies the possibility of providing a separate insurance product/service that covers daily life and travel activities together. More importantly, in the post-COVID-19 era, travel insurance companies should focus more on communication between potential customers to effectively communicate the benefits and coverage of their insurance products (Tan and Caponecchia 2021). Third, this study can be used to determine the possible price of a new insurance product. The average price per day of existing travel insurance products in South Korea was calculated to be KRW 1280 (USD 1.12). Given our initial bid amounts (ranging from KRW 1000 to KRW 4000), the estimated average WTP in our study (KRW 11,699.9, USD 10.24) was extremely high possibly because of the severity of the COVID-19 pandemic at the time of data collection. This result suggests that the price of a special travel insurance product may have room to increase given a specific risk situation. Fourth, our study revealed differences in the results (e.g., the effect of risk perception and WTP) between groups with varying experiences in purchasing travel insurance, thus suggesting the importance of customer relationship management. Travel insurance companies should provide enhanced customer experience through measures such as providing an easy claim system and ensuring a quick response. Companies also need to maintain good relationships with their existing customers and make sure that potential tourists are aware of insurance products and available services. Finally, tourism destinations or companies (e.g., hotels, airlines) could consider including a complimentary travel insurance policy in their regular products and promote such products and information. A collaboration between online travel agencies and insurance companies could enhance the attractiveness of tourism products and services, which will eventually make tourists choose certain products or destinations.

\subsection{Limitations and future research}

This study provides several theoretical and practical implications. Nonetheless, certain limitations and intriguing findings are identified, and they should be useful in guiding further studies and investigations. First, this study did not consider the actual willingness to travel in its investigation of purchasing travel insurance. Although this study attempted to follow the guidelines for designing a realistic CVM scenario, our findings may be inflated due to unknown reasons. Thus, future research needs to incorporate respondents' willingness to travel into the analytic framework. Second, this study did not consider the possible unobserved heterogeneity in the responses. A finite mixture model could be an alternative analytic method for dealing with such heterogeneity and assist in identifying several different groups of respondents who 
have different characteristics and risk sensitivities. Third, many possible personal factors (e.g., personality, past experience in claiming insurance, travel expertise) were not considered in this study. Future research could include such variables to provide fruitful theoretical and managerial implications. Fourth, risk perception could vary depending on the destination or travel type, whereas this study did not consider a specific destination. Thus, future research could consider destination characteristics (e.g., type of destination, type of attachment) or travel characteristics (e.g., international vs. domestic, travel party), which can moderate the relationship between risk perception and travel insurance. Finally, this study was conducted at the very early stage of the COVID-19 pandemic and did not incorporate any recent developments such as health passports, vaccines, and similar measures. Thus, future studies must incorporate such developments and changes in the situation.

Funding The authors did not receive support from any organization for the submitted work.

\section{Declarations}

Conflict of interest The authors have no relevant financial or non-financial interests to disclose.

\section{References}

An M, Lee C, Noh Y (2010) Risk factors at the travel destination: their impact on air travel satisfaction and repurchase intention. Serv Bus 4(2):155-166

Arrow J, Solow R, Portney PR, Leamer E, Radner R, Schumand H (1993) Report of the NOAA panel on contingent valuation to the general council of the US national oceanic and atmospheric administration. Resources for the Future, Washington, DC

Baloglu S, McCleary KW (1999) A model of destination image formation. Ann Tour Res 26(4):868-897. https://doi.org/10.1016/s0160-7383(99)00030-4

Boyle KJ, Welsh MP, Bishop RC (1988) Validation of empirical measures of welfare change: comment. Land Econ 64(1):94-98

Chen S, Law R, Zhang M (2020) Review of research on tourism-related diseases. Asia Pac J Tour Res. https://doi.org/10.1080/10941665.2020.1805478

Chew EYT, Jahari SA (2014) Destination image as a mediator between perceived risks and revisit intention: a case of post-disaster Japan. Tour Manag 40:382-393. https://doi.org/10.1016/j.tourman. 2013.07.008

Chien PM, Sharifpour M, Ritchie BW, Watson B (2016) Travelers' health risk perceptions and protective behavior: a psychological approach. J Travel Res 56(6):744-759. https://doi.org/10.1177/00472 87516665479

Chou P-L, Yao C-H (2011) Applying a mixed logit model approach to analyze china's travel insurance decision-making behavior. J Stat Manag Syst 14(6):1057-1066. https://doi.org/10.1080/09720510. 2011.10701601

Chua B-L, Al-Ansi A, Lee MJ, Han H (2021) Impact of health risk perception on avoidance of international travel in the wake of a pandemic. Curr Issue Tour 24(7):985-1002

Cossar J (2003) Travellers' health: an epidemiological overview. In: Wilks J, Page SJ (eds) Managing tourist health and safety in the new millennium. Pergamon, Oxford, pp 19-33

Darby AC, Hiscox JA (2021) Covid-19: variants and vaccination. BMJ 372:n771. https://doi.org/10.1136/ bmj.n771

Dolnicar S (2013) Asking good survey questions. J Travel Res 52(5):551-574. https://doi.org/10.1177/ 0047287513479842 
Fuchs G, Reichel A (2006) Tourist destination risk perception: the case of Israel. J Hosp Leis Mark 14(2):83-108. https://doi.org/10.1300/J150v14n02_06

Fuchs G, Reichel A (2011) An exploratory inquiry into destination risk perceptions and risk reduction strategies of first time vs. repeat visitors to a highly volatile destination. Tour Manag 32(2):266-276. https://doi.org/10.1016/j.tourman.2010.01.012

Gössling S, Scott D, Hall CM (2020) Pandemics, tourism and global change: a rapid assessment of COVID-19. J Sustain Tour 29(1):1-20. https://doi.org/10.1080/09669582.2020.1758708

Hanemann WM (1994) Valuing the environment through contingent valuation. J Econ Perspect 8(4):19-43

Hanemann WM, Loomis J, Kanninen B (1991) Statistical efficiency of double-bounded dichotomous choice contingent valuation. Am J Agr Econ 73(4):1255-1263

Hasan AA, Abdullah NC (2015) Compulsory travel insurance in Malaysia: some regulatory considerations. Proc Soc Behav Sci 172:344-351. https://doi.org/10.1016/j.sbspro.2015.01.375

Jonas A, Mansfeld Y, Paz S, Potasman I (2010) Determinants of health risk perception among low-risktaking tourists traveling to developing countries. J Travel Res 50(1):87-99. https://doi.org/10.1177/ 0047287509355323

Jung J (2021) A long way to the recovery: COVID-19 will not disappear. J Korean Med Sci. https://doi. org/10.3346/jkms.2021.36.e231

Karl M (2018) Risk and uncertainty in travel decision-making: tourist and destination perspective. J Travel Res 57(1):129-146. https://doi.org/10.1177/0047287516678337

Kerr G, Kelly L (2018) Travel insurance: the attributes, consequences, and values of using travel insurance as a risk-reduction strategy. J Travel Tour Mark 36(2):191-203. https://doi.org/10.1080/10548 408.2018.1506376

Kock F, Norfelt A, Josiassen A, Assaf AG, Tsionas MG (2020) Understanding the COVID-19 tourist psyche: the evolutionary tourism paradigm. Ann Tour Res 85:103053. https://doi.org/10.1016/j.annals. 2020.103053

Krinsky I, Robb AL (1990) On approximating the statistical properties of elasticities: a correction. Rev Econ Stat 72(1):189-190

Lebrun A-M, Corbel R, Bouchet P (2021) Impacts of Covid-19 on travel intention for summer 2020: a trend in proximity tourism mediated by an attitude towards Covid-19. Serv Bus. https://doi.org/10. 1007/s11628-021-00450-z

Lee C-K, Song H-J, Bendle LJ, Kim M-J, Han H (2012) The impact of non-pharmaceutical interventions for 2009 H1N1 influenza on travel intentions: a model of goal-directed behavior. Tour Manag 33(1):89-99

Leggat PA, Leggat FW (2002) Travel insurance claims made by travelers from Australia. J Travel Med 9(2):59-65

Leggat PA, Carne J, Kedjarune U (1999) Travel insurance and health. J Travel Med 6(4):243-248. https:// doi.org/10.1111/j.1708-8305.1999.tb00526.x

Lo AS, Cheung C, Law R (2011) Hong Kong residents' adoption of risk reduction strategies in leisure travel. J Travel Tour Mark 28(3):240-260. https://doi.org/10.1080/10548408.2011.562851

McFadden D (1974) The measurement of urban travel demand. J Public Econ 3(4):303-328

Mitchell VW, Vassos V (1998) Perceived risk and risk reduction in holiday purchases: a cross-cultural and gender analysis. J Euromarketing 6(3):47-79

Mitchell RC, Carson RT, Carson RT (1989) Using surveys to value public goods: the contingent valuation method. Resources for the Future, Washington, DC

Mizrachi I, Fuchs G (2016) Should we cancel? An examination of risk handling in travel social media before visiting ebola-free destinations. J Hosp Tour Manag 28:59-65. https://doi.org/10.1016/j.jhtm. 2016.01.009

Phelan AL (2020) COVID-19 immunity passports and vaccination certificates: scientific, equitable, and legal challenges. Lancet 395(10237):1595-1598

Pizam A, Jeong G-H, Reichel A, van Boemmel H, Lusson JM, Steynberg L, State-Costache O, Volo S, Kroesbacher C, Kucerova J (2004) The relationship between risk-taking, sensation-seeking, and the tourist behavior of young adults: a cross-cultural study. J Travel Res 42(3):251-260

Reichel A, Fuchs G, Uriely N (2007) Perceived risk and the non-institutionalized tourist role: the case of Israeli student ex-backpackers. J Travel Res 46(2):217-226. https://doi.org/10.1177/0047287507 299580

Roehl WS, Fesenmaier DR (1992) Risk perceptions and pleasure travel: an exploratory analysis. J Travel Res 30(4):17-26. https://doi.org/10.1177/004728759203000403 
Sarman I, Scagnolari S, Maggi R (2016) Acceptance of life-threatening hazards among young tourists. J Travel Res 55(8):979-992. https://doi.org/10.1177/0047287515612595

Sarman I, Curtale R, Hajibaba H (2019) Drivers of travel insurance purchase. J Travel Res 59(3):545558. https://doi.org/10.1177/0047287519843187

Schreyer R, Lime DW, Williams DR (1984) Characterizing the influence of past experience on recreation behavior. J Leis Res 16(1):34-50

Shi W, Li KX (2017) Impact of unexpected events on inbound tourism demand modeling: evidence of Middle East Respiratory Syndrome outbreak in South Korea. Asia Pac J Tour Res 22(3):344-356

Sigala M (2020) Tourism and COVID-19: impacts and implications for advancing and resetting industry and research. J Bus Res 117:312-321. https://doi.org/10.1016/j.jbusres.2020.06.015

Song H, Witt SF, Li G (2008) The advanced econometrics of tourism demand. Routledge, Milton Park

Sonmez SF, Graefe AR (1998a) Determining future travel behavior from past travel experience and perceptions of risk and safety. J Travel Res 37(2):171-177. https://doi.org/10.1177/004728759803700 209

Sonmez SF, Graefe AR (1998b) Influence of terrorism risk on foreign tourism decisions. Ann Tour Res 25(1):112-144. https://doi.org/10.1016/S0160-7383(97)00072-8

Tan D, Caponecchia C (2021) COVID-19 and the public perception of travel insurance. Ann Tour Res 90:103106

Tykocinski OE (2008) Insurance, risk, and magical thinking. Pers Soc Psychol Bull 34(10):1346-1356. https://doi.org/10.1177/0146167208320556

UNWTO (2020) World tourism barometer 18(5). https://doi.org/10.18111/wtobarometereng

Uriely N, Maoz D, Reichel A (2007) Rationalising terror-related risks: the case of Israeli tourists in Sinai. Int J Tour Res 9(1):1-8. https://doi.org/10.1002/jtr.587

Wen J, Kozak M, Yang S, Liu F (2020) COVID-19: potential effects on Chinese citizens' lifestyle and travel. Tour Rev. https://doi.org/10.1108/tr-03-2020-0110

Wilks J (2006) Current issues in tourist health, safety and security. Tourism in turbulent times. Routledge, Milton Park, pp 27-42

Wilks J, Pendergast D, Leggat P (2006) Tourism in turbulent times. Routledge, Milton Park

Williams AM, Baláž V (2013) Tourism, risk tolerance and competences: travel organization and tourism hazards. Tour Manag 35:209-221

Williams AM, Baláž V (2015) Tourism risk and uncertainty: theoretical reflections. J Travel Res 54(3):271-287

Yu T-W, Chen T-J (2018) Online travel insurance purchase intention: a transaction cost perspective. J Travel Tour Mark 35(9):1175-1186. https://doi.org/10.1080/10548408.2018.1486781

Zalech M (2020) Socio-demographic features and risk perception as determinants of taking out travel insurance. Tour Anal. https://doi.org/10.3727/108354220x15957949047195

Publisher's Note Springer Nature remains neutral with regard to jurisdictional claims in published maps and institutional affiliations. 